(C) 2022, The Authors. Published by Elsevier Inc. and Fass Inc. on behalf of the American Dairy Science Association ${ }^{\circledR}$. This is an open access article under the CC BY license (http://creativecommons.org/licenses/by/4.0/).

\title{
Views of Western Canadian dairy producers on calf rearing: An interview-based study
}

Elizabeth R. Russell, (i) Marina A. G. von Keyserlingk, (D) and Daniel M. Weary* (D)

Animal Welfare Program, Faculty of Land and Food Systems, The University of British Columbia, 2357 Main Mall, Vancouver, BC V6T 1Z4, Canada

\section{ABSTRACT}

Calf rearing practices differ among farms, including feeding and weaning methods. These differences may relate to how dairy producers view these practices and evaluate their own success. The aim of this study was to investigate perspectives of dairy producers on calf rearing, focusing on calf weaning and how they characterized weaning success. We interviewed dairy producers from 16 farms in Western Canada in the following provinces: British Columbia $(\mathrm{n}=12)$, Manitoba $(\mathrm{n}=$ $2)$, and Alberta $(\mathrm{n}=2)$. Participants were asked to describe their heifer calf weaning and rearing practices, and what they viewed as successes and challenges in weaning and rearing calves. Interviews were recorded, transcribed, and subjected to qualitative analysis from which we identified the following 4 major themes: (1) reliance on calf-based measures (e.g., health, growth, and behavior), (2) management factors and personal experiences (e.g., ease, consistency, and habit), (3) environmental factors (e.g., facilities and equipment), and (4) external support (e.g., advice and educational opportunities). These results provided insight into how dairy producers view calf weaning and rearing, and may help inform the design of future research and knowledge transfer projects aimed at improving management practices on dairy farms.

Key words: qualitative method, calf management, heifer rearing, animal welfare

\section{INTRODUCTION}

Milk feeding of dairy calves and the transition from milk to solid feed at weaning are 2 challenging phases to manage. Despite evidence that calves can consume approximately $10 \mathrm{~L} / \mathrm{d}$ of milk (Appleby et al., 2001; Rosenberger et al., 2017), calves are often only offered

Received August 4, 2021.

Accepted October 24, 2021.

*Corresponding author: dan.weary@ubc.ca
10 to $12 \%$ of their BW $(4-6 \mathrm{~L} / \mathrm{d})$ in milk or milk replacer (e.g., Vasseur et al., 2010). Feeding restricted milk allowances is associated with prolonged hunger, as evidenced by the high number of unrewarded visits to automatic feeders (Jensen and Holm, 2003; Jensen, 2006; De Paula Vieira et al., 2008) and lower locomotor play behavior (Jensen et al., 2015). An advantage to feeding higher milk allowances (e.g., approximately $20 \%$ of BW) is increased ADG in preweaning calves and higher overall body growth (Khan et al., 2007; Jafari et al., 2020). Increased growth in preweaning calves has been associated with increased first-lactation milk yield (Heinrichs and Heinrichs, 2011; Soberon et al., 2012; Van De Stroet et al., 2016) and lower age at first calving (Moallem et al., 2010).

Calves are often weaned from milk at approximately 8 wk of age (Vasseur et al., 2010; USDA, 2016), a process that is performed earlier and more abruptly than what would occur in nature (Weary et al., 2008). Distress during the weaning period has been evaluated using behavioral indicators, including increased vocalizations (De Passillé et al., 2010; Fröberg et al., 2011), increased unrewarded visits to the automatic feeder (Jensen, 2006), and decreased play behavior (Krachun et al., 2010). Solid feed intake before weaning has been used as an indicator of a calf's ability to transition to solid feed, with starter intake often used as an indicator by producers (Vasseur et al., 2010; Le Cozler et al., 2012; Phipps et al., 2018). A suggested calf starter intake of roughly $1.5 \mathrm{~kg} / \mathrm{d}$ for 3 consecutive days is a commonly used industry recommendation (Bovine Alliance on Management and Nutrition, 2017). Calves fed higher milk allowances tend to consume less starter before weaning (Khan et al., 2007), but gradually weaning calves from high milk allowances using individual intake targets can help reduce weaning age and maintain BW after weaning (Benetton et al., 2019). In addition, calves on a step-down (gradual) weaning protocol consume more feed and have greater BW compared with calves weaned abruptly (Khan et al., 2007). Gradually weaning calves from high milk allowances can also reduce cross-suckling (Nielsen et al., 2008). 
Despite this research-based evidence, little is known about the practices that dairy producers use to wean their calves. Work to date on calf rearing practices (Canada: Vasseur et al., 2010; Brazil: Hötzel et al., 2014; Czech Republic: Staněk et al., 2014; United States: USDA, 2016; Germany: Hayer et al., 2021) indicates considerable variation in feeding and management of calves among and within regions. Survey-based research can show "what" producers do but does not explain "why" they do what they do. There has been an increase in work evaluating farmer attitudes, motivations, and perceptions toward calf rearing practices, such as disease control (calf illness and mortality; Vaarst and Sørensen, 2009), painful procedures (dehorning; Cardoso et al., 2016), and farm management (identification of young stock management hazards; Boersema et al., 2013). One recent study evaluated the perceptions of English dairy producers and advisors on the adoption of different milk feeding protocols (Palczynski et al., 2020); this study found that some producers fed restricted milk allowances and used inconsistent weaning protocols, a result the authors attributed to poor guidance from advisors, reflecting historical rather than science-based practices. The aim of this study was to investigate producer views toward heifer rearing, with a focus on calf weaning. We sought to understand why producers rear calves the way they do, and what practices they view as successful or challenging. We adopted a qualitive approach to explore participant experiences and perspectives (Dicicco-Bloom and Crabtree, 2006; Gill et al., 2008), to better understand the reasoning behind different rearing practices, and thus, to inform future research and extension efforts.

\section{MATERIALS AND METHODS}

This study was approved by The University of British Columbia's Behavioral Research Ethics Board (H19-01195), and all participants gave verbal consent to participate. Data were collected from July to September 2020 .

\section{Recruitment}

We recruited a convenience sample (Robinson, 2014) of dairy cattle producers in Western Canada. To be included in the study, participants had to be actively dairy farming in Western Canada, have a minimum 10 dairy heifers being reared on the farm at the time of the interview, and be responsible for making decisions regarding calf management (i.e., they were the farm owner, manager, calf feeder, or calf manager). Participants were recruited via industry contacts (e.g., feed manufacturing companies), media outlets (e.g., breed- associated publications and provincial milk organization newsletters), and by word of mouth. Twenty dairy producers were recruited; due to scheduling conflicts, 2 producers were unable to arrange a time to be interviewed and did not participate in the study. The number of participants was not predetermined; interviews continued until thematic saturation, described as when no new ideas were apparent in additional interviews (Guest et al., 2006). Recruitment material included a single-page document outlining the research objectives, participant requirements, description of how the study was to be conducted, and researcher contact information. Dairy producers were encouraged to contact the first author (E. R.) via phone or email if they were interested in participating in the study. Potential participants were then provided additional information regarding consent and a time was scheduled for the interview to take place.

\section{Participants}

A total of 18 individuals (10 men and 8 women) were interviewed from 16 different dairy farms in the following provinces in Western Canada: British Columbia $(\mathrm{n}=12)$, Manitoba $(\mathrm{n}=2)$, and Alberta $(\mathrm{n}=2)$. Participants were identified as being the farm manager or owner $(\mathrm{n}=15)$ or calf caretaker or manager $(\mathrm{n}=3)$. Herd size ranged from 75 to 540 lactating cows (Table 1). Calf housing, feeding, and weaning practices varied by farm (Table 2). All interviews were with a single participant, except for 2 interviews where 2 participants represented a single farm.

Table 1. Farm demographics for the 16 farms included in this study

\begin{tabular}{lccl}
\hline $\begin{array}{l}\text { Participant } \\
\text { ID }^{1}\end{array}$ & $\begin{array}{c}\text { Number of } \\
\text { employees }^{2}\end{array}$ & $\begin{array}{c}\text { Number of } \\
\text { lactating cows }\end{array}$ & Breed $^{3}$ \\
\hline P10 & 5 & 160 & Holstein \\
P12 & 7 & 105 & Holstein \\
P16 & 7 & 150 & Holstein \\
P18 & 14 & $535-540$ & Holstein \\
P24 & 3 & 75 & Holstein \\
P28 & 5 & 120 & Holstein \\
P38 and P51 & 4 & $260-270$ & Holstein \\
P43 & 4 & 120 & Holstein \\
P44 & Not stated & $75-80$ & Holstein \\
P61 and P66 & 5 & 460 & Mixed \\
P70 & 7 & $140-150$ & Mixed \\
P72 & 7 & $105-115$ & Holstein \\
P74 & 3 & $78-90$ & Mixed \\
P77 & 5 & 103 & Holstein \\
P79 & 7 & 200 & Holstein \\
P83 & $180-200$ & Mixed \\
\hline
\end{tabular}

${ }^{1}$ Participant (P) identification number.

${ }^{2}$ Number includes participant(s) and family labor.

${ }^{3}$ Mixed includes Holsteins and 1 or more other breeds. 
Russell et al.: PRODUCER VIEWS ON CALF REARING

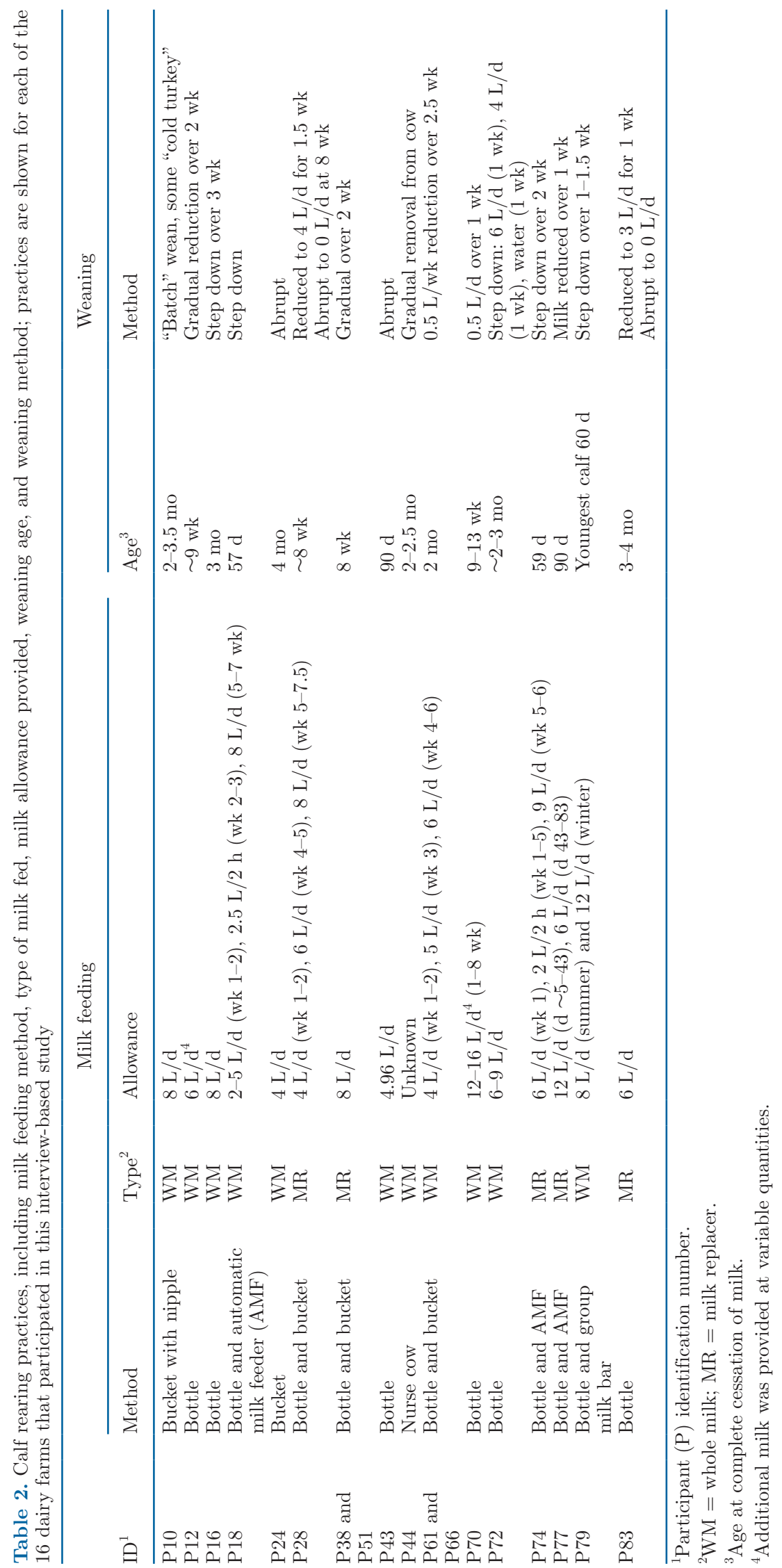


To protect confidentiality, participants were randomly assigned participant (P) identification numbers (ID), represented as PID (e.g., P10) for the quotes presented in the text. Some of the quotes provided in the text were modified with ellipses for missing text, and include square brackets (i.e., [...]) to represent text that was modified to improve clarity. Quotes were selected based on clarity and relevance to the theme described.

\section{Interviews}

Semi-structured interviews fostered a guided discussion with participants while allowing for the discovery of additional information (Dilley, 2000). Due to restrictions associated with the COVID-19 pandemic, all interviews took place via a video $(\mathrm{n}=13)$ or phone call $(\mathrm{n}=3)$, depending on the participant's preference. Interviews were audio recorded and lasted between 30 and 70 min (mean $\pm \mathrm{SD} ; 47 \pm 11 \mathrm{~min}$ ). Interviews began with an introduction of the researcher (E. R.), study objectives, and warm-up questions [e.g., questions about the participant(s), farm demographics, and other small talk] with the intention of building rapport between the participant and interviewer (Dilley, 2000). Participants were then asked a series of questions to better understand how they raised calves, specifically heifers from newborn to first breeding, what they view as being challenging and successful practices, how they define a successful weaning, and their view of the future of calf and heifer rearing. In addition to these primary questions, the interviewer followed up with secondary questions to explore some points in greater detail. Participants were also given the opportunity to ask the interviewer questions throughout the interview. Before starting the study, 2 pilot interviews were conducted to ensure that questions were phrased in such ways that the research objectives were met. Pilot interviews were not included in the final data analysis. All interviews were carried out by E. R. using a critical realist perspective (Archer et al., 1998). Interviewer E. R. is a woman and, at the time of this study, was a master's of science student. She came to the study with a background in dairy science and experience working on dairy farms in the United States and Canada.

\section{Method of Analysis}

Audio recordings were listened to by E. R. to ensure the quality of recording and to remove any identifying information. Fieldnotes were taken during the interviews by E. R. but were not included in data analysis. Recordings were then uploaded to a transcription service and transcribed verbatim into a text file. E. R. reviewed the transcriptions with the audio recording to ensure the accuracy of the transcribed file. Transcripts were then sent to each participant for review and corrections; 1 participant provided additional updated information that was added to their interview, and no corrections were requested. Transcriptions were subjected to thematic analysis by E. R. using NVivo 12 (QSR International). Thematic content analysis was selected because of its ability to provide a rich description of data (Braun and Clarke, 2006; Bard et al., 2019). An inductive approach was taken with the creation of the codebook, where the development of codes was driven by the data (Braun and Clarke, 2012). Meaningful pieces of texts (line-by-line) that were related to research questions were manually sorted into codes, which developed into an initial codebook (Miles et al., 2014). Initial codes were generated during transcription review, which occurred after each interview. Thematic saturation was determined when no new parent codes were generated from additional interviews. More in-depth codebook development was done in NVivo 12 after thematic saturation was determined and all interviews were completed. The initial codebook was then sent to a second researcher trained in qualitative methods, along with 2 transcripts to review for intercoder reliability. The codebook, codes, and themes were discussed between the 2 researchers. The generation of the codebook was an iterative process and, upon reflection and revisions, the codebook was finalized and used to code all interviews by E. R.

\section{RESULTS AND DISCUSSION}

Participants discussed what they considered to be factors that contributed to challenges and successes of calf rearing, including weaning success. From the analysis of these interviews, the following 4 main themes emerged: (1) reliance on calf-based indicators; (2) management and personal experiences; (3) environmental influences; and (4) integration of external farm support.

\section{Reliance on Calf-Based Indicators}

When describing their views regarding successes in calf rearing, participants relied heavily on calf-based indicators, including behavior, growth, and health. Reliance on calf-based indicators is consistent with a long history of research on dairy calf rearing that has focused on measures such as feed intake, growth, and, more recently, behavior (reviewed by Kertz et al., 2017).

Behavior. When discussing feeding behaviors, participants recognized the importance of feeding high milk allowances and calf ability to consume large quantities of milk early in life; for instance, P18 said, "... we really pound the milk into them early, which they 
drink voluntarily... lots of them are just drinking 11 to 12 liters," and "... some of my babies are drinking .... 12 to 16 liters of milk a day. And that seems to help a lot..." (P70). In addition, P72 credited feeding higher milk allowances to increased growth and smoother transitions at weaning, "... since I started feeding the calves more milk, I see the calves, the growth, [they're] way 'growthier'. They just do better, they transition better." However, one participant (P38), who fed higher milk allowances in the past, expressed concerns about solid feed intake when feeding higher milk allowances, stating, "I guess the challenge for us at that time is the program [Automated milk feeder (AMF)] allowed [calves] to consume up to 10 liters of milk a day. And the grain consumption was really hard to get going at that time." This illustrated the importance that some participants saw in using solid feed intake as an indicator of weaning success, a point echoed by P43 who stated, "Successfully weaned is you know; they're going strong in the sense that they're consuming that grain when you put it in front of them you know, and they lap it all up [and] they're eating hay...." The majority of participants recognized the importance of feeding high milk allowances, reflecting research showing the benefits to feeding calves more milk (Soberon et al., 2012; Miller-Cushon et al., 2013). Similarly, other studies have reported that solid feed intake is used by producers as an indicator of a calf's ability to transition from milk to solid feed (Le Cozler et al., 2012). Hesitancy to feed higher milk allowances was centered around concern regarding solid feed intake. As observed by P38, calves fed high milk allowances can have reduced starter intakes before weaning compared with calves fed restricted allowances (Dennis et al., 2018; Jafari et al., 2020); although, gradually weaning calves from milk, especially when feeding high milk allowances, can promote solid feed intake with minimal growth check (e.g., Khan et al., 2007).

Participants emphasized the social behavior of calves, including play. Play was seen as an indicator of a successful calf rearing program by P16, "I just want to see them up and jumping around a little bit." Participants also mentioned calf vocalizations when asked to describe indicators of successful calf weaning. "...I guess we've done a good job if you can't hear them once we've weaned them when they go to the group pens," said P12. Similarly, P16 commented, "I basically don't want to hear them freaking out too much about a change in their situation. So, like, if they're really freaking out, I feel like I did it [weaning] too fast." However, others including P10 saw vocalizations as normal and not a basis for concern, adding, "So... they whine and bitch for about five or six days, and moan and groan, and then they get over it... And it's a bit loud, but hey, yeah, no one's ever starved to death on this farm." Research has shown that vocalizations can be indicative of hunger (Thomas et al., 2001; Manteuffel et al., 2004). Vocalizations around feeding may also be specifically directed toward human caregivers responsible for milk feeding (Watts and Stookey, 2000; De Paula Vieira et al., 2008).

Some participants discussed the affective states of calves, for example using the word "happy" to describe calves during weaning and housing transitions; P44, who reared calves on a nurse cow, expressed it was challenging to keep calves and cows "happy" during weaning and said, "Well that's the tricky part because they, neither the cow nor the calf, is very happy then [at weaning]." Other participants recognized housing transitions (e.g., from individual hutches to group pens) as being a source of "stress" for calves; P83 discussed the transition from individual housing in hutches to group housing as "a huge stressor for them to go from something that they've been in, you know, for such a long period of time." P18 wondered if there was a way to mitigate calf stress during housing transitions with the use of pharmaceuticals and stated, "I don't know if we gave them like some sort of a painkiller when they move... I don't know if that would help just limit some of the stress that they have." Producers have been known to focus more on measures associated with basic health and functioning rather than on affective states or natural living criteria aspects of animal welfare (e.g., Tuyttens et al., 2010; Albernaz-Gonçalves et al., 2021). However, the recognition of affective states by participants in this study is consistent with previous work showing that producers recognize that cattle experience emotions (Bertenshaw and Rowlinson, 2009).

Calf Growth. Calf growth was described as an indicator of a successful calf rearing program. Continued BW gains after weaning were viewed as important, as mentioned by P16, saying, "...I want to see them continuing to gain weight; don't want to see them going backwards... that [is the] challenge - to keep them moving forward." Some participants monitored weight gains to gauge success. Doubling birth weight was seen as a way to gauge success of the preweaning rearing programs and was used by some to decide when to start weaning; P74 saw their ability to double calf birth weight in the first $50 \mathrm{~d}$ as a way to reduce the amount of milk fed to calves, "I mean by 50 days, they're double their birth weight. Why bother feeding them an expensive product when they can move off..." Participant awareness of feed costs in relation to growth does not come as a surprise as feed costs are the largest expense in rearing replacement heifers (Heinrichs et al., 2013).

Rapid BW gains before and after weaning allow breeding at younger ages, and breeding age was used as 
an indicator of a successful rearing program. "We are breeding our heifers now at 12 or 13 months, if I wasn't doing that, I would maybe go back and revisit what are we doing wrong. But we're breeding them early. They're calving out early. So, I'm imagining that we must be successful in what we're doing," P10 stated. Participant recognition of growth and reproductive outcomes aligned with literature on rearing replacement heifers, where these outcome measures were often used to monitor calf and heifer management and coincide well with feeding practices (reviewed by Heinrichs et al., 2017).

Calf Morbidity and Mortality. Maintaining calf health was viewed as a challenge in calf rearing, as stated by P12 as follows: "There's nothing more depressing than having a calf barn full of sick calves." Health challenges varied depending on calf age. Diarrhea was considered a challenge within the first $2 \mathrm{wk}$ of life; one participant stated, "...scours is probably our biggest challenge at times" (P38). For older calves, participants cited additional health concerns, such as pneumonia and parasitic infections including coccidiosis and cryptosporidiosis. P16 mentioned their struggle with pneumonia, "probably less than half ... get a bit of pneumonia at some point along the way... So that's another thing I say we struggle with a little bit is some pneumonia in the calves." P61 referred to coccidiosis as being "... kind of a big thing." Participant P16 noted an issue with cryptosporidiosis that was "very hard to get reduced." Diarrhea in young calves, poor growth during the milk feeding phase, and parasitic infections in weaned calves were also identified as concerns of Dutch dairy producers (Boersema et al., 2013). Reports in the United States show mortality at roughly $6.4 \%$ and $1.9 \%$ for preweaning and weaned heifers respectively; diarrhea is responsible for more than half the preweaning deaths, and respiratory illness is the leading cause of mortality in weaned calves (USDA, 2018).

In addition to concerns about disease and parasites in calves, participants viewed a low mortality rate as a key indicator of a successful rearing program. Low mortality was a source of pride. Participants stated, "I think we have a very low mortality rate. You know, it's really got to be about $2 \%$ of calves in the calf barn that leave without walking out. So, we're proud of that" (P24) and "... [My brother has] the same amount of quota, same number of robots and stuff like that. And every fall, we do our inventory and I've got about 15 to $20 \%$ more heifers all the time. And it's just a simple mortality rate difference" (P12). "...that's why we have so many replacement stock... it's because of that [low mortality rate], you know, we just don't lose animals here," said P43, highlighting the desired outcome of achieving a low mortality. Increased calf mortality can be an indicator of poor management (e.g., poor colostrum feeding, milk feeding and weaning practices) and negative welfare (Mellor and Stafford, 2004; Zucali et al., 2013), and results in economic losses (Boulton et al., 2017). Sumner et al. (2018a) also found that British Columbian dairy producers perceived low mortality as an indicator of success. Future work would benefit from collecting data on calf mortality and using this context to better understand participants' views; previous work suggests that producers sometimes underestimate calf mortality on their farms, reducing motivation to change practices (Vaarst and Sørensen, 2009; Vasseur et al., 2012).

\section{Management and Personal Experiences}

Participants viewed their personal experiences in managing calves as critical to the successes of the calf rearing program. Consistency and ease of practices, managing conflicts on the farm, capacity for observation, and experiences were all considered important.

Employees. Having designated employees responsible for calf care was considered beneficial by participants. On 2 farms, the interviews included both the owner and the primary calf-caregiver. In both cases, the owners credited the calf-caregiver with a portion of the success as follows: "I know I don't have to worry about the newborn to weaning because [the calf-caregiver has] got that covered," (P61, owner) and "I don't have to take care of it. [the calf-caregiver] does such a good job" (P38, owner). Management practices on farm play a critical role in calf health and mortality (Seppä-Lassila et al., 2016; Abuelo et al., 2019). Recent work (Hayer et al., 2021) found that farms that had hired a calf rearing employee were more likely to complete crucial management practices properly (e.g., feed colostrum early, disbud calves within the first 2 wk of life, and maintain hygienic practices, such as pen cleaning and navel disinfection).

The quantity and classification (e.g., family or not) of employees was seen as contributing to success. P24 acknowledged that having designated employees for calf care was limited by farm size by saying, "The success is that on some of these large farms they have one or a team of people dedicated to one component of the farm." Many of the participating farms had both family and nonfamily employees. Most participants worked with family members on the farm, which followed the typical structure of dairy farming in Canada (Statistics Canada, 2016). In the United States, smaller operations (>250 cows) are also likely to rely on family labor (Schewe and White, 2017). P12 mentioned that having only family employees made calf weaning time variable and sometimes dependent on family functions, "... be- 
ing a family run thing, [a] two week [weaning period] is a little bit variable. Sometimes it depends on what baseball [game] we're going to and who remembers and who doesn't remember." In contrast, P10 mentioned problems in observing and treating calf illness when working with inexperienced nonfamily employees, stating, "Not throwing anybody under the bus, but [employee name] still has challenges in that early recognition [of calf illness]."

Consistency and Ease of Practices for Producers. Consistency of milk feeding practices is often considered a high priority (Hill et al., 2009). Our participants believed that consistency was important in calf rearing, especially during the milk feeding phase. One participant (P28) cited their choice to feed milk replacer as a way to maintain consistency, "... they get milk replacer... hundred percent milk replacer...that way, it's always consistent." A few participants felt that consistency was challenged by variable staffing schedules. For example, P66 said, "... you really have to pay attention and kind of know what's going on in the barn. And if you have too many people, I think, then they don't know the calves. They don't notice little inconsistencies or things that will change." P12 advocated for the use of standard operating procedures (SOP) to maintain this consistency, saying, "Big perspective view, I would say just move to protocols, SOP. That was a game changer for us. It just made it so much easier to tell the next person what we do." Standard operating procedures are increasingly requested in animal care assessments (e.g., Dairy Farmers of Canada ProAction, 2020; National Milk Producers Federation, 2020) and can be useful in ensuring practices remain consistent (De Treville et al., 2005) and for training (Barbé et al., 2016). Although our study did not focus on the use of SOP, the challenge of working with inexperienced employees suggests some value to adopting this approach; recent work has shown that the uptake of SOP varies among farms (Mills et al., 2020a), suggesting the need for extension efforts focused on this topic.

Participants saw importance in the "ease" of a task. One participant stated, "If it's easy, it gets done" (P10). More specifically, "easiness" of milk feeding practices and weaning programs were thought to be important. In one case (P12), the decision to wean calves was dependent upon when it was "convenient for the [calf] feeder..." This result was also seen with English dairy producers, where ease of calf management was viewed as influential on calf feeding practices (Palczynski et al., 2020).

Constraints and Conflicts. Time availability was seen a constraint. For example, P61 felt that a lack of time made it difficult to keep facilities clean and said the following: "We do try to clean their pens as much as possible, as much as we can and as much as time allows us to." The lack of time has also been reported by dairy producers as a limiting factor in reducing lameness on farms (Leach et al., 2010).

Interpersonal conflict was mentioned as a challenge. P83, who worked on the family farm, said "... I do receive pressure from you know, the man above me. [They] will say 'you are taking too long to wean these calves." P74 mentioned differences among family members in recognizing problems on the farm; "I realized that calf barn ventilation is just a matter of 'I can smell the ammonia [but] my husband can't'. So, I will tell him it needs to be cleaned out and he's going 'nope, doesn't stink', I said, 'yes, it does, so do it."'

Experience and Habit. Participants cited personal experiences to justify rearing practices: "Just sort of the way we've always done it," said P28. Weaning procedures were often based upon personal experience and what participants believed worked well on their farm. "I've been taking care of calves on this farm since I was in like elementary school. So, I've really watched [the calves], I've learned what seems to make them happy, what works" (P16). Likewise, P24 reflected on the role of experience, but also recognized their own complacency, "I've been doing this all my life, but it's a mix of things I've learned over the years and maybe [I am] set in my ways, I don't know." Similarly, Wilson et al. (2021) reported that dairy producers developed calf care practices primarily from personal experiences. A person's previous experience contributes to decision making and willingness to change and has been highlighted in previous studies on producer adoption of biosecurity measures (Ritter et al., 2017). Previous experience with negative situations (e.g., disease outbreak) is likely to motivate producers to implement new management (e.g., biosecurity measures) in the future (Moya et al., 2020). Producers may feel as though they have an understanding of best practices, but this often comes from experience rather than specific training (Garforth et al., 2013).

Habit and tradition were identified as influencing rearing practices. P43 recognized that, "there's probably best practices [for weaning] that are better... but I'm just telling you how we do it right now... because that's traditionally what we've done...." Producer and employee habit, experience, and personal routine can be a barrier to the implementing practices, as seen with milking practices (Belage et al., 2019). Furthermore, farm tradition can affect implementation of new rearing practices. For instance, Brazilian dairy producers reported farm tradition as justification for continuing calf rearing practices harmful for calf welfare (e.g., limit milk feeding, painful procedures; Hötzel et al., 2014). 
Calf and Heifer Observations. Careful observation of calves was believed to be important. P24 emphasized the need for regular daily observations of calves and the importance of having an experienced observer, "I do a walk through [the calf barn] a couple extra times a day. I think an experienced eye is part of our success." However, observations declined as calves aged and began to be perceived as more mature heifers. Participants felt that once calves were weaned and moved to different pens, observations were not necessarily needed. "Everything at that stage [postweaning] is straight forward," said (P77) and "Postweaning really, we don't look at them other than issues," said P74. One participant (P83) noted that the observation and care of calves after weaning was insufficient; "I do think that like, from weaning till first breeding, our heifers are very neglected. Very neglected. Which happens quite often on farms, right?" This shift in focus may reflect the common practice of moving calves to different facilities after weaning, often with reduced observation (Heinrichs et al., 1987; Pettersson et al., 2001). Previous work has evaluated how the treatment of calves before weaning affects outcomes such as age at first calving, milk yield, and growth (Moallem et al., 2010; Davis Rincker et al., 2011). Although these studies followed calves from newborn to first lactation, they also typically focused on the preweaning period with little information on calves after weaning. The lack of focus on heifers from weaning to breeding is consistent with the limited number of studies on the effects of management practices during this period. Decreased observations of older calves likely also related to the participants' priorities, with older calves considered to be a lower priority than younger calves. Lai et al. (2019) found that US dairy producers ranked calf and heifer management as the second most important management area (behind milk production management). However, Lai et al. (2019) lumped together calf and heifer rearing in 1 category; we suggest that producers interviewed in this study may have placed more weight on calves than heifers, and thus we encourage future work to explore whether this is representative of most dairy producers.

In addition, clarification of the definition of "heifer" may be necessary as usage varied among participants. Some participants defined "heifer" as a specific age range, stating, "If I was to take a stab at it, I would probably say six months of age for me, okay." (P43). However, some participants gave definitions based on when calves transitioned to a new pen, stating, "yeah, it's really just when it [the calf/heifer] gets moved to a specific barn for us...It's not really an age thing." (P77). A few participants also defined heifers immedi- ately upon birth with the following statements: "They are classified here...as a replacement heifer for us within the first 24 hours" (P74) and "I call them "heifer calves' right from the get-go." (P61). Interestingly, variability in terminology was identified as an issue when dairy producers and veterinarians appeared to use the term "transition period" differently (Mills et al., 2020b), acting as a potential barrier to communication.

\section{Environmental Influences}

Participants perceived and discussed several environmental influences on calf weaning and rearing outcomes, including the effects of facilities and equipment.

Facilities and Equipment. Participants described the effects of facilities and equipment on calf weaning and rearing outcomes. Farm facilities were thought to have an important influence. Space limitations were mentioned with emphasis on keeping calves moving through the rearing system. P18 said, "We're trying to cycle as many calves through the facilities that we have, without losing body weight or conditioning..." P61 noted that although not ideal for calves, moving calves to different pens often was necessary due to space limitations, "We do move them quite a bit, which is not always ideal, but it is what it is, because it's what we have for facilities." Ventilation was recognized as crucial to calf health, with poor ventilation perceived as a risk for respiratory illness. Participants who had improved ventilation reported decreased pneumonia as follows: "We did have quite a bit of pneumonia in our calf barn prior to putting a positive pressure tube in," (P70) and "[We] went to a positive pressure air tube about a year ago. And that's probably been one of the biggest improvements on our calf rearing, minimizing pneumonia" (P38). The presence of respiratory disease has been reported to be influenced by ventilation and housing style, along with other management factors (e.g., colostrum management, nutrition, and weaning strategies; Lago et al., 2006; Gorden and Plummer, 2010).

Calf housing style (e.g., individual, group, pair, or nurse cow) and cleanliness were also viewed as contributing to rearing success, but views varied regarding preferred housing systems. Some participants preferred to rear calves individually, citing perceived health benefits and ease of monitoring, "... with the hutches. I can definitely see how much they eat. And I feel like that's a huge thing for me" (P83). However, other participants felt that group housing improved a calf's ability to transition at weaning and increased play behavior as follows: "...we used to find when we took our calves out of hutches, they had never experienced anything 
but being in a hutch. So now they're in pairs. And then in groups...So our transition is very smooth." (P79) and "They're kicking up their heels and bellering and you just see they're having fun; they're playing with each other. So, I [would have] a really hard time putting calves back in a hutch when I see how well they do in a group setting" (P44). Participants who discussed the benefits to housing calves socially recognized the benefits of social rearing, including reduced fear responses and increased play (Costa et al., 2016). Additional benefits to social housing include improved solid feed intake (De Paula Vieira et al., 2010) and increased growth (Miller-Cushon and DeVries, 2016).

The use of AMF and milk pasteurizers were viewed as positive to participants who used these. Participants with AMF commented on their ability to manage milk allowances for sustained growth. One participant stated, "So basically, a success in our barn is the milk feeder and utilizing proper feeding at a young age" (P74). Participants who had AMF believed weaning calves using a computerized system was easy, as shown with the following statements: "The computer feeders are really good for that because they really can just slow down the milk consumption and the calves slowly drink more water and [eat] more feed," (P18) and "...that's the part I love about the milk feeder. I mean don't have to sit and think about, 'okay, you're being weaned...' the program does it for me." (P74). However, not all participants had access to AMF. P44 raised calves on a nurse cow and described this method as the "... a poor man's version of an automated calf feeder. Without the headache of cleaning and mechanical maintenance." As AMF becomes a more available to producers, it is important to understand producer motivations for adopting this technology, including improved milk feeding practices, reduced labor, and improved working conditions (Medrano-Galarza et al., 2017).

\section{Integration of External Farm Support}

Participants discussed how external farm support affected calf rearing, including relationships with veterinarians and peers, and educational opportunities.

External Advice. It is important that farm support comes from those who are known to the producers and understand what occurs on farm (Croyle et al., 2019). Participants considered veterinarians as trusted advisors to calf rearing, a finding that is similar to that reported by Sumner et al. (2018b). A few of the participants were enrolled in calf programs with their veterinary clinic, which included testing $\operatorname{IgG}$ levels, weighing calves, administering vaccinations, and disbudding. Those enrolled in these programs conveyed that their veterinarian was a resource for monitoring calf health and growth. Similarly, previous work has identified veterinarians as trusted advisors for animal health and management (Chase et al., 2006; Pothmann et al., 2014). Overall, participants found it important to have a good relationship with their veterinarian. One participant found value in their veterinarian's background as a dairy farmer, stating, "... our [veterinarian] always says our calves look great. And [the veterinarian's] a dairy farmer, or he's from a dairy farming family, so he gets the whole thing about calves," said P72. Fostering a good relationship with the veterinarian helped build trust, an essential component of the farmer-veterinarian relationship, facilitating changes on farm (Bard et al., 2019; Svensson et al., 2019).

Not all farms and participants had access to calf monitoring programs. One participant (P43) reflected on their struggle accessing this service, "... my vet[erinarian] has some strengths, but he has some weaknesses too. And I don't really see him as that detail guy who wants...to set up a program. Let's say it's on young calf health, and really monitor all those things, it's not really in his wheelhouse...."

In addition to veterinarians, advice from peers was described as valuable. Peers were identified as other dairy producers and those involved with the dairy industry. Participants looked to peers for advice on feeding and weaning, equipment, and methods of observing calf growth and health. Access to a network of peers can be important to producers as a form of information sharing (Martínez-García et al., 2015) and has been regarded by veterinarians as an opportunity for learning and a motivator for change (Roche et al., 2019). Moreover, producers identified as proactive, defined as those who are well informed and interested in new developments, find advice from peers especially helpful (Jansen et al., 2010). The use of benchmarking, which compares performance among peers with the intent to improve performance of specific indicators, can be an effective way of motivating behavioral change in dairy producers (Chapinal et al., 2014; Sumner et al., 2018a). Furthermore, the curation of benchmarking with guidance from veterinarians can strengthen producers' perceptions of the veterinarian as an advisor in calf management (Sumner et al., 2020). Previous work on colostrum management found that the majority of participants made at least one change to their colostrum management program after receiving benchmark reports, suggesting that having identifiable measurements can assist in achieving change (Atkinson et al., 2017). Future research should examine the effect of benchmarking calf performance around weaning on improving management practices during this period. 
Educational Opportunities. Participants viewed seminars, conferences, and industry publications as useful resources in developing calf rearing practices, as was reported by Wilson et al. (2021). P61 described how information at a conference prompted the development of the milk feeding and weaning program they used, "When I first came in with my husband... they didn't really have a weaning practice. My father-in-law went to a conference, and they talked about going up and then taking the milk down... So, then he started that [weaning program]." The use of conferences to make informed decisions showed the value of extension opportunities; these can have a positive effect on farmer adoption of practices (Baumgart-Getz et al., 2012). One participant made the decision to pair house calves based upon an article they read in an industry publication. P16 said, "I read an article in the Progressive Dairyman that basically went over all of the calf raising and pair raising benefits...I said, 'Okay, I definitely need to keep on this [group housing]. I can't revert back. I want to keep it up', because I felt that those things were important benefits for the calves."

\section{DISCUSSION}

The findings from this study provide insight into producer views on calf rearing, focusing on the weaning period. The results of this study may help in the development of future research on calf management. Future research should further investigate variation in rearing practices on farm by measuring success using the indicators recognized by participants in this study (e.g., feed intake, body growth, and health). Future studies should also consider influential factors such as management, use of facilities, and access to learning opportunities (knowledge transfer), along with support, including producers' relationships with veterinarians and peers.

We took a qualitative approach, providing a detailed description of producer views, but there are several limitations to this study. Data collection took place during the COVID-19 pandemic, and participant recruitment was limited to producers who were willing to be interviewed over video or by telephone call. In addition, the pandemic brought uncertainty for some participants that may have affected calf management. The results from this study are not intended to be generalizable. Participants in this study were Western Canadian dairy producers who reared replacement stock on farm, many of whom were familiar with the University of British Columbia's Animal Welfare Program and Dairy Education and Research Centre. Results may be different for other participants, including those who farm in different regions of the world.

\section{CONCLUSIONS}

Producers in our study characterized weaning and rearing success using multiple factors. First, participants relied on calf-based indicators such as calf growth, health, and behavior, to determine weaning and rearing success. Second, management practices such as employee management and personal experience were regarded as important influences on how calves were weaned and reared and represented as both successes and challenges. Finally, the rearing environment, equipment, and external advice were viewed as contributing to overall rearing success.

\section{ACKNOWLEDGMENTS}

We thank the participants for sharing their time and thoughts, and the people who assisted in participant recruitment, including Josh Ferguson with Ritchie Smith Feeds, Tars Cheema with BC Holstein News, and representatives of the BC Dairy Association, Dairy Farmers of Manitoba, SaskMilk, and Alberta Milk. We also thank our colleagues within the Animal Welfare Program for their support throughout this study. General funding for the UBC Animal Welfare program is provided by the Natural Science and Engineering Research Council's Research Chair in Dairy Cattle Welfare awarded to DMW and MvK with contributions from our industrial partners the Dairy Farmers of Canada (Ottawa, ON, Canada), Saputo Inc. (Montreal, QC, Canada), British Columbia Dairy Association (Burnaby, BC Canada), Alberta Milk (Edmonton, AB, Canada), Intervet Canada Corporation (Kirkland, QC, Canada), Boehringer Ingelheim Animal Health (Burlington, ON, Canada), BC Cattle Industry Development Fund (Kamloops, BC, Canada), The Semex Alliance (Guelph, ON, Canada), Lactanet (Sainte-Anne-de-Bellevue, QC, Canada), Dairy Farmers of Manitoba (Winnipeg, MB, Canada), and SaskMilk (Regina, SK, Canada). The authors have not stated any conflicts of interest.

\section{REFERENCES}

Abuelo, A., P. Havrlant, N. Wood, and M. Hernandez-Jover. 2019 An investigation of dairy calf management practices, colostrum quality, failure of transfer of passive immunity, and occurrence of enteropathogens among Australian dairy farms. J. Dairy Sci. 102:8352-8366. https://doi.org/10.3168/jds.2019-16578.

Albernaz-Gonçalves, R., G. Olmos, and M. J. Hötzel. 2021. My pigs are ok, why change? - Animal welfare accounts of pig farmers. Animal 15:100154. https://doi.org/10.1016/j.animal.2020.100154.

Appleby, M. C., D. M. Weary, and B. Chua. 2001. Performance and feeding behaviour of calves on ad libitum milk from artificial teats. Appl. Anim. Behav. Sci. 74:191-201. https://doi.org/10.1016/ S0168-1591(01)00171-X.

Archer, M., R. Bhaskar, A. Collier, T. Lawson, and A. Norrie. 1998. Critical Realism: Essential Readings. Routledge. 
Atkinson, D. J., M. A. G. von Keyserlingk, and D. M. Weary. 2017. Benchmarking passive transfer of immunity and growth in dairy calves. J. Dairy Sci. 100:3773-3782. https://doi.org/10.3168/jds .2016-11800.

Barbé, B., K. Verdonck, D. Mukendi, V. Lejon, J.-R. Lilo Kalo, E. Alirol, P. Gillet, N. Horié, R. Ravinetto, E. Bottieau, C. Yansouni, A. S. Winkler, H. Van Loen, M. Boelaert, P. Lutumba, and J. Jacobs. 2016. The art of writing and implementing standard operating Procedures (SOPs) for laboratories in low-resource settings: Review of guidelines and best practices. PLoS Negl. Trop. Dis. 10:e0005053. https://doi.org/10.1371/journal.pntd.0005053.

Bard, A. M., D. Main, E. Roe, A. Haase, H. R. Whay, and K. K. Reyher. 2019. To change or not to change? Veterinarian and farmer perceptions of relational factors influencing the enactment of veterinary advice on dairy farms in the United Kingdom. J. Dairy Sci. 102:10379-10394. https://doi.org/10.3168/jds.2019-16364.

Baumgart-Getz, A., L. S. Prokopy, and K. Floress. 2012. Why farmers adopt best management practice in the United States: A metaanalysis of the adoption literature. J. Environ. Manage. 96:17-25. https://doi.org/10.1016/j.jenvman.2011.10.006.

Belage, E., S. L. Croyle, A. Jones-Bitton, S. Dufour, and D. F. Kelton. 2019. A qualitative study of Ontario dairy farmer attitudes and perceptions toward implementing recommended milking practices. J. Dairy Sci. 102:9548-9557. https://doi.org/10.3168/jds.2018 -15677 .

Benetton, J. B., H. W. Neave, J. H. C. Costa, M. A. G. von Keyserlingk, and D. M. Weary. 2019. Automatic weaning based on individual solid feed intake: Effects on behavior and performance of dairy calves. J. Dairy Sci. 102:5475-5491. https://doi.org/10 $.3168 /$ jds.2018-15830.

Bertenshaw, C., and P. Rowlinson. 2009. Perceptions of the humananimal relationship on dairy farms and an association with milk production. Anthrozoos 22:59-69. https://doi.org/10.2752/ $175303708 X 390473$.

Boersema, J. S. C., J. P. T. M. Noordhuizen, and J. J. Lievaart. 2013. Hazard perception of Dutch farmers and veterinarians related to dairy young stock rearing. J. Dairy Sci. 96:5027-5034. https://doi .org/10.3168/jds.2012-6276.

Boulton, A. C., J. Rushton, and D. C. Wathes. 2017. An empirical analysis of the cost of rearing dairy heifers from birth to first calving and the time taken to repay these costs. Animal 11:1372-1380. https://doi.org/10.1017/S1751731117000064.

Bovine Alliance on Management \& Nutrition (BAMN). 2017. A guide to feeding and weaning healthy and productive dairy calves. BAMN.

Braun, V., and V. Clarke. 2006. Using thematic analysis in psychology. Qual. Res. Psychol. 3:77-101. https://doi.org/10.1191/ 1478088706qp063oa.

Braun, V., and V. Clarke. 2012. Thematic analysis. American Psychological Association.

Cardoso, C. S., M. A. G. von Keyserlingk, and M. J. Hötzel. 2016. Trading off animal welfare and production goals: Brazilian dairy farmers' perspectives on calf dehorning. Livest. Sci. 187:102-108. https://doi.org/10.1016/j.livsci.2016.02.010.

Chapinal, N., D. M. Weary, L. Collings, and M. A. G. von Keyserlingk. 2014. Lameness and hock injuries improve on farms participating in an assessment program. Vet. J. 202:646-648. https://doi.org/10 $.1016 / j . t v j l .2014 .09 .018$.

Chase, L. E., L. O. Ely, and M. F. Hutjens. 2006. Major advances in extension education programs in dairy production. J. Dairy Sci. 89:1147-1154. https://doi.org/10.3168/jds.S0022-0302(06)72183 -X.

Costa, J. H. C., M. A. G. von Keyserlingk, and D. M. Weary. 2016. Invited review: Effects of group housing of dairy calves on behavior, cognition, performance, and health. J. Dairy Sci. 99:2453-2467. https://doi.org/10.3168/jds.2015-10144.

Croyle, S. L., E. Belage, D. K. Khosa, S. J. LeBlanc, D. B. Haley, and D. F. Kelton. 2019. Dairy farmers' expectations and receptivity regarding animal welfare advice: A focus group study. J. Dairy Sci. 102:7385-7397. https://doi.org/10.3168/jds.2018-15821.
Dairy Farmers of Canada ProAction. 2020. Dairy Farmers of Canada: ProAction-on Farm Excellence. Accessed July, 15, 2021. https:// www.dairyfarmers.ca/proaction.

Davis Rincker, L. E., M. J. VandeHaar, C. A. Wolf, J. S. Liesman, L. T. Chapin, and M. S. Weber Nielsen. 2011. Effect of intensified feeding of heifer calves on growth, pubertal age, calving age, milk yield, and economics. J. Dairy Sci. 94:3554-3567. https://doi.org/ 10.3168/jds.2010-3923.

De Passillé, A. M., B. Sweeney, and J. Rushen. 2010. Cross-sucking and gradual weaning of dairy calves. Appl. Anim. Behav. Sci. 124:11-15. https://doi.org/10.1016/j.applanim.2010.01.007.

De Paula Vieira, A., V. Guesdon, A. M. de Passillé, M. A. G. von Keyserlingk, and D. M. Weary. 2008. Behavioural indicators of hunger in dairy calves. Appl. Anim. Behav. Sci. 109:180-189. https://doi .org/10.1016/j.applanim.2007.03.006.

De Paula Vieira, A., M. A. G. von Keyserlingk, and D. M. Weary. 2010. Effects of pair versus single housing on performance and behavior of dairy calves before and after weaning from milk. J. Dairy Sci. 93:3079-3085. https://doi.org/10.3168/jds.2009-2516.

De Treville, S., J. Antonakis, and N. M. Edelson. 2005. Total quality management and business excellence can standard operating procedures be motivating? Reconciling process variability issues and behavioural outcomes. Total Qual. Manage. Bus. Excell. 16:231241. https://doi.org/10.1080/14783360500054236.

Dennis, T. S., F. X. Suarez-Mena, T. M. Hill, J. D. Quigley, R. L. Schlotterbeck, and L. Hulbert. 2018. Effect of milk replacer feeding rate, age at weaning, and method of reducing milk replacer to weaning on digestion, performance, rumination, and activity in dairy calves to 4 months of age. J. Dairy Sci. 101:268-278. https:/ /doi.org/10.3168/jds.2017-13692.

Dicicco-Bloom, B., and B. F. Crabtree. 2006. The qualitative research interview. Med. Educ. 40:314-321. https://doi.org/10.1111/j.1365 $-2929.2006 .02418 . x$.

Dilley, P. 2000. Conducting successful interviews: Tips for intrepid research. Theory Pract. 39:131-137. https://doi.org/10.1207/ s15430421tip3903_3.

Fröberg, S., L. Lidfors, K. Svennersten-Sjaunja, and I. Olsson. 2011. Performance of free suckling dairy calves in an automatic milking system and their behaviour at weaning. Acta Agric. Scand. A Anim. Sci. 61:145-156. https://doi.org/10.1080/09064702.2011 .632433 .

Garforth, C. J., A. P. Bailey, and R. B. Tranter. 2013. Farmers' attitudes to disease risk management in England: A comparative analysis of sheep and pig farmers. Prev. Vet. Med. 110:456-466. https://doi.org/10.1016/j.prevetmed.2013.02.018.

Gill, P., K. Stewart, E. Treasure, and B. Chadwick. 2008. Methods of data collection in qualitative research: interviews and focus groups. Br. Dent. J. 204:291-295. https://doi.org/10.1038/bdj.2008.192.

Gorden, P. J., and P. Plummer. 2010. Control, management, and prevention of bovine respiratory disease in dairy calves and cows. Vet. Clin. North Am. Food Anim. Pract. 26:243-259. https://doi.org/ 10.1016/j.cvfa.2010.03.004.

Guest, G., A. Bunce, and L. Johnson. 2006. How many interviews are enough?: An experiment with data saturation and variability. Field Methods 18:59-82. https://doi.org/10.1177/1525822X05279903.

Hayer, J. J., D. Nysar, C. Heinemann, C. D. Leubner, and J. SteinhoffWagner. 2021. Implementation of management recommendations in unweaned dairy calves in western Germany and associated challenges. J. Dairy Sci. 104:7039-7055. https://doi.org/10.3168/jds .2020-19829.

Heinrichs, A. J., and B. S. Heinrichs. 2011. A prospective study of calf factors affecting first-lactation and lifetime milk production and age of cows when removed from the herd. J. Dairy Sci. 94:336-341. https://doi.org/10.3168/jds.2010-3170.

Heinrichs, A. J., C. M. Jones, S. M. Gray, P. A. Heinrichs, S. A. Cornelisse, and R. C. Goodling. 2013. Identifying efficient dairy heifer producers using production costs and data envelopment analysis. J. Dairy Sci. 96:7355-7362. https://doi.org/10.3168/jds.2012-6488.

Heinrichs, A. J., N. E. Kiernan, R. E. Graves, and L. J. Hutchinson. 1987. Survey of calf and heifer management practices in Penn- 
sylvania dairy herds. J. Dairy Sci. 70:896-904. https://doi.org/10 .3168/jds.S0022-0302(87)80090-5.

Heinrichs, A. J., G. I. Zanton, G. J. Lascano, and C. M. Jones. 2017. A 100-Year Review: A century of dairy heifer research. J. Dairy Sci. 100:10173-10188. https://doi.org/10.3168/jds.2017-12998.

Hill, T. M., H. G. Bateman Ii., J. M. Aldrich, and R. L. Schlotterbeck. 2009. Effect of consistency of nutrient intake from milk and milk replacer on dairy calf performance. Prof. Anim. Sci. 25:85-92. https://doi.org/10.15232/S1080-7446(15)30679-3.

Hötzel, M. J., C. Longo, L. F. Balcão, C. S. Cardoso, and J. H. C. Costa. 2014. A survey of management practices that influence performance and welfare of dairy calves reared in southern Brazil. PLoS One 9:e114995. https://doi.org/10.1371/journal.pone.0114995.

Jafari, A., A. Azarfar, G. R. Ghorbani, M. Mirzaei, M. A. Khan, H. Omidi-Mirzaei, A. Pakdel, and M. H. Ghaffari. 2020. Effects of physical forms of starter and milk allowance on growth performance, ruminal fermentation, and blood metabolites of Holstein dairy calves. J. Dairy Sci. 103:11300-11313. https://doi.org/10 $.3168 /$ jds.2020-18252.

Jansen, J., C. D. M. Steuten, R. J. Renes, N. Aarts, and T. J. G. M. Lam. 2010. Debunking the myth of the hard-to-reach farmer: Effective communication on udder health. J. Dairy Sci. 93:12961306. https://doi.org/10.3168/jds.2009-2794.

Jensen, M. B. 2006. Computer-controlled milk feeding of group-housed calves: The effect of milk allowance and weaning type. J. Dairy Sci. 89:201-206. https://doi.org/10.3168/jds.S0022-0302(06)72084-7.

Jensen, M. B., L. R. Duve, and D. M. Weary. 2015. Pair housing and enhanced milk allowance increase play behavior and improve performance in dairy calves. J. Dairy Sci. 98:2568-2575. https://doi . org $/ 10.3168 /$ jds.2014-8272

Jensen, M. B., and L. Holm. 2003. The effect of milk flow rate and milk allowance on feeding related behaviour in dairy calves fed by computer controlled milk feeders. Appl. Anim. Behav. Sci. 82:87100. https://doi.org/10.1016/S0168-1591(03)00054-6.

Kertz, A. F., T. M. Hill, J. D. Quigley III, A. J. Heinrichs, J. G. Linn, and J. K. Drackley. 2017. A 100-Year Review: Calf nutrition and management. J. Dairy Sci. 100:10151-10172. https://doi.org/10 $.3168 /$ jds.2017-13062

Khan, M. A., H. J. G. Lee, W. S. Lee, H. S. Kim, S. B. Kim, K. S. Ki, J. K. Ha, H. J. G. Lee, and Y. J. Choi. 2007. Pre- and postweaning performance of Holstein female calves fed milk through step-down and conventional methods. J. Dairy Sci. 90:876-885. https://doi .org/10.3168/jds.S0022-0302(07)71571-0.

Krachun, C., J. Rushen, and A. M. de Passillé. 2010. Play behaviour in dairy calves is reduced by weaning and by a low energy intake. Appl. Anim. Behav. Sci. 122:71-76. https://doi.org/10.1016/ j.applanim.2009.12.002

Lago, A., S. M. McGuirk, T. B. Bennett, N. B. Cook, and K. V. Nordlund. 2006. Calf respiratory disease and pen microenvironments in naturally ventilated calf barns in winter. J. Dairy Sci. 89:40144025. https://doi.org/10.3168/jds.S0022-0302(06)72445-6.

Lai, J., N. J. O. Widmar, and C. A. Wolf. 2019. Dairy farm management priorities and implications. Int. Food Agribus. Manag. Rev. 22:15-30. https://doi.org/10.22434/IFAMR2018.0010.

Le Cozler, Y., O. Recoursé, E. Ganche, D. Giraud, J. Danel, M. Bertin, and P. Brunschwig. 2012. A survey on dairy heifer farm management practices in a Western-European plainland, the French Pays de la Loire region. J. Agric. Sci. 150:518-533. https://doi.org/10 $1017 /$ S0021859612000032

Leach, K. A., H. R. Whay, C. M. Maggs, Z. E. Barker, E. S. Paul, A. K. Bell, and D. C. J. Main. 2010. Working towards a reduction in cattle lameness: 2. Understanding dairy farmers' motivations. Res. Vet. Sci. 89:318-323. https://doi.org/10.1016/j.rvsc.2010.02.017.

Manteuffel, G., B. Puppe, and P. C. Schön. 2004. Vocalization of farm animals as a measure of welfare. Appl. Anim. Behav. Sci. 88:163182. https://doi.org/10.1016/j.applanim.2004.02.012.

Martínez-García, C. G., S. J. Ugoretz, C. M. Arriaga-Jordán, and M. A. Wattiaux. 2015. Farm, household, and farmer characteristics associated with changes in management practices and technology adoption among dairy smallholders. Trop. Anim. Health Prod. 47:311-316. https://doi.org/10.1007/s11250-014-0720-4.
Medrano-Galarza, C., S. J. Leblanc, A. Jones-Bitton, T. J. DeVries, J. Rushen, A. M. de Passillé, and D. B. Haley. 2017. Producer perceptions of manual and automated milk feeding systems for dairy calves in Canada. Can. J. Anim. Sci. 98:250-259. https://doi.org/ 10.1139/cjas-2017-0038.

Mellor, D. J., and K. J. Stafford. 2004. Animal welfare implications of neonatal mortality and morbidity in farm animals. Vet. J. 168:118-133. https://doi.org/10.1016/j.tvjl.2003.08.004.

Miles, M. B., A. M. Huberman, and J. Saldana. 2014. Qualitative Data Analysis. 3rd ed. SAGE Publications Inc.

Miller-Cushon, E. K., R. Bergeron, K. E. Leslie, and T. J. DeVries. 2013. Effect of milk feeding level on development of feeding behavior in dairy calves. J. Dairy Sci. 96:551-564. https://doi.org/10 $.3168 /$ jds.2012-5937.

Miller-Cushon, E. K., and T. J. DeVries. 2016. Effect of social housing on the development of feeding behavior and social feeding preferences of dairy calves. J. Dairy Sci. 99:1406-1417. https://doi.org/ 10.3168/jds.2015-9869.

Mills, K. E., K. E. Koralesky, D. M. Weary, and M. A. G. von Keyserlingk. 2020a. Dairy farmer advising in relation to the development of standard operating procedures. J. Dairy Sci. 103:11524-11534. https://doi.org/10.3168/jds.2020-18487.

Mills, K. E., D. M. Weary, and M. A. G. von Keyserlingk. 2020b. Identifying barriers to successful dairy cow transition management. J. Dairy Sci. 103:1749-1758. https://doi.org/10.3168/jds.2018-16231.

Moallem, U., D. Werner, H. Lehrer, M. Zachut, L. Livshitz, S. Yakoby, and A. Shamay. 2010. Long-term effects of ad libitum whole milk prior to weaning and prepubertal protein supplementation on skeletal growth rate and first-lactation milk production. J. Dairy Sci. 93:2639-2650. https://doi.org/10.3168/jds.2009-3007.

Moya, S., F. Tirado, J. Espluga, G. Ciaravino, R. Armengol, J. Diéguez, E. Yus, B. Benavides, J. Casal, and A. Allepuz. 2020. Dairy farmers' decision-making to implement biosecurity measures: A study of psychosocial factors. Transbound. Emerg. Dis. 699-710. https://doi.org/10.1111/tbed.13387.

National Milk Producers Federation. 2020. FARM: Animal Care Animal Care. Accessed Jun. 21, 2021. https://nationaldairyfarm.com/ farm-animal-care-version-4-0/.

Nielsen, P. P., M. B. Jensen, and L. Lidfors. 2008. Milk allowance and weaning method affect the use of a computer controlled milk feeder and the development of cross-sucking in dairy calves. Appl. Anim. Behav. Sci. 109:223-237. https://doi.org/10.1016/j.applanim.2007 .01 .015 .

Palczynski, L. J., E. C. L. Bleach, M. L. Brennan, and P. A. Robinson. 2020. Appropriate dairy calf feeding from birth to weaning: "it's an investment for the future. Animals (Basel) 10:116. https://doi .org/10.3390/ani10010116.

Pettersson, K., C. Svensson, and P. Liberg. 2001. Housing, feeding and management of calves and replacement heifers in Swedish dairy herds. Acta Vet. Scand. 42:465-478. https://doi.org/10.1186/1751 $-0147-42-465$.

Phipps, A. J., D. S. Beggs, A. J. Murray, P. D. Mansell, and M. F. Pyman. 2018. A survey of northern Victorian dairy farmers to investigate dairy calf management: Calf-rearing practices. Aust. Vet. J. 96:107-110. https://doi.org/10.1111/avj.12686.

Pothmann, H., K. Nechanitzky, F. Sturmlechner, and M. Drillich. 2014. Consultancy to dairy farmers relating to animal health and herd health management on small- and medium-sized farms. J. Dairy Sci. 97:851-860. https://doi.org/10.3168/jds.2013-7364.

Ritter, C., J. Jansen, S. Roche, D. F. Kelton, C. L. Adams, K. Orsel, R. J. Erskine, G. Benedictus, T. J. G. M. Lam, and H. W. Barkema. 2017. Invited review: Determinants of farmers' adoption of management-based strategies for infectious disease prevention and control. J. Dairy Sci. 100:3329-3347. https://doi.org/10.3168/ jds.2016-11977.

Robinson, O. C. 2014. Sampling in interview-based qualitative research: A theoretical and practical guide. Qual. Res. Psychol. 11:25-41. https://doi.org/10.1080/14780887.2013.801543.

Roche, S. M., D. F. Kelton, M. Meehan, M. Von Massow, and A. JonesBitton. 2019. Exploring dairy producer and veterinarian perceptions of barriers and motivators to adopting on-farm management 
practices for Johne's disease control in Ontario, Canada. J. Dairy Sci. 102:4476-4488. https://doi.org/10.3168/jds.2018-15944.

Rosenberger, K., J. H. C. Costa, H. W. Neave, M. A. G. von Keyserlingk, and D. M. Weary. 2017. The effect of milk allowance on behavior and weight gains in dairy calves. J. Dairy Sci. 100:504-512. https://doi.org/10.3168/jds.2016-11195.

Schewe, R. L. R. L., and B. White. 2017. Who works here? Contingent labor, nonfamily labor, and immigrant labor on U.S. dairy farms. Soc. Currents 4:429-447. https://doi.org/10.1177/ 2329496516686539 .

Seppä-Lassila, L., K. Sarjokari, M. Hovinen, T. Soveri, and M. Norring. 2016. Management factors associated with mortality of dairy calves in Finland: A cross sectional study. Vet. J. 216:164-167. https://doi.org/10.1016/j.tvjl.2016.07.008.

Soberon, F., E. Raffrenato, R. W. Everett, and M. E. Van Amburgh. 2012. Preweaning milk replacer intake and effects on long-term productivity of dairy calves. J. Dairy Sci. 95:783-793. https://doi .org/10.3168/jds.2011-4391.

Staněk, S., V. Zink, O. Doležal, and L. Štolc. 2014. Survey of preweaning dairy calf-rearing practices in Czech dairy herds. J. Dairy Sci. 97:3973-3981. https://doi.org/10.3168/jds.2013-7325.

Statistics Canada. 2016. Statistics Canada: Table 32-10-0433-1. Farms classified by operating arrangement. Accessed July 18, 2021. https: //www150.statcan.gc.ca/t1/tbl1/en/tv.action?pid=3210043301.

Sumner, C. L., M. A. G. von Keyserlingk, and D. M. Weary. 2018a. How benchmarking motivates farmers to improve dairy calf management. J. Dairy Sci. 101:3323-3333. https://doi.org/10.3168/jds .2017-13596

Sumner, C. L., M. A. G. von Keyserlingk, and D. M. Weary. 2018b. Perspectives of farmers and veterinarians concerning dairy cattle welfare. Anim. Front. 8:8-13. https://doi.org/10.1093/af/vfx006.

Sumner, C. L., M. A. G. von Keyserlingk, and D. M. Weary. 2020 How benchmarking promotes farmer and veterinarian cooperation to improve calf welfare. J. Dairy Sci. 103:702-713. https://doi.org/ $10.3168 /$ jds.2019-16338.

Svensson, C., N. Lind, K. K. Reyher, A. M. Bard, and U. Emanuelson. 2019. Trust, feasibility, and priorities influence Swedish dairy farmers' adherence and nonadherence to veterinary advice. J. Dairy Sci. 102:10360-10368. https://doi.org/10.3168/jds.2019 $-16470$.

Thomas, T. J., D. M. Weary, and M. C. Appleby. 2001. Newborn and 5-week-old calves vocalize in response to milk deprivation. Appl. Anim. Behav. Sci. 74:165-173. https://doi.org/10.1016/S0168 -1591(01)00164-2.

Tuyttens, F. A. M., F. Vanhonacker, E. Van Poucke, and W. Verbeke. 2010. Quantitative verification of the correspondence between the Welfare Quality ${ }^{\circledR}$ operational definition of farm animal welfare and the opinion of Flemish farmers, citizens and vegetarians. Livest. Sci. 131:108-114. https://doi.org/10.1016/j.livsci.2010.03.008.
USDA. 2016. Dairy 2014: Dairy Cattle Management Practices in the United States, 2014. USDA. Accessed Nov. 19, 2021. https://www .aphis.usda.gov/animal_health/nahms/dairy/downloads/dairy14/ Dairy14_dr_PartI_1.pdf.

USDA. 2018. Health and Management Practices on U.S. Dairy Operations, 2014. USDA. Accessed Nov. 19, 2021. https://www .aphis.usda.gov/animal_health/nahms/dairy/downloads/dairy14/ Dairy14_dr_PartIII.pdf.

Vaarst, M., and J. T. Sørensen. 2009. Danish dairy farmers' perceptions and attitudes related to calf-management in situations of high versus no calf mortality. Prev. Vet. Med. 89:128-133. https:/ /doi.org/10.1016/j.prevetmed.2009.02.015.

Van De Stroet, D. L., J. A. Calderón Díaz, K. J. Stalder, A. J. Heinrichs, and C. D. Dechow. 2016. Association of calf growth traits with production characteristics in dairy cattle. J. Dairy Sci 99:8347-8355. https://doi.org/10.3168/jds.2015-10738.

Vasseur, E., F. Borderas, R. I. Cue, D. Lefebvre, D. Pellerin, J. Rushen, K. M. Wade, and A. M. de Passillé. 2010. A survey of dairy calf management practices in Canada that affect animal welfare. J. Dairy Sci. 93:1307-1315. https://doi.org/10.3168/jds.2009-2429.

Vasseur, E., D. Pellerin, A. M. De Passillé, C. Winckler, B. J. Lensink, U. Knierim, and J. Rushen. 2012. Assessing the welfare of dairy calves: Outcome-based measures of calf health versus input-based measures of the use of risky management practices. Anim. Welf. 21:77-86. https://doi.org/10.7120/096272812799129439.

Watts, J. M., and J. M. Stookey. 2000. Vocal behaviour in cattle: The animal's commentary on its biological processes and welfare. Appl. Anim. Behav. Sci. 67:15-33. https://doi.org/10.1016/S0168 -1591(99)00108-2.

Weary, D. M., J. Jasper, and M. J. Hötzel. 2008. Understanding weaning distress. Appl. Anim. Behav. Sci. 110:24-41. https://doi.org/ 10.1016/j.applanim.2007.03.025.

Wilson, D. J., J. A. Pempek, S. M. Roche, K. C. Creutzinger, S. R. Locke, G. Habing, K. L. Proudfoot, K. A. George, and D. L. Renaud. 2021. A focus group study of Ontario dairy producer perspectives on neonatal care of male and female calves. J. Dairy Sci. 104:6080-6095. https://doi.org/10.3168/jds.2020-19507.

Zucali, M., L. Bava, A. Tamburini, M. Guerci, and A. Sandrucci. 2013. Management risk factors for calf mortality in intensive Italian dairy farms. Ital. J. Anim. Sci. 12:e26. https://doi.org/10.4081/ ijas.2013.e26.

\section{ORCIDS}

Elizabeth R. Russell ๑ https://orcid.org/0000-0001-9202-439X

Marina A. G. von Keyserlingk (1) https://orcid.org/0000-0002-1427 $-3152$

Daniel M. Weary @ https://orcid.org/0000-0002-0917-3982 